\title{
Improving access to lung cancer treatment in northern Canada: the role of oral molecularly targeted agents
}

\author{
Johanna N. Spaans MSc, Timothy R. Asmis MD, Gonzalo G. Alvarez MD, Glenwood D. Goss MD
}

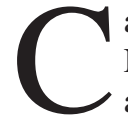
anadians with cancer who live in the North experience a number of barriers to accessing diagnostic and treatment services. Accumulating evidence suggests that the travel burden experienced by cancer patients in remote and rural communities may influence their treatment choices. ${ }^{1}$ Some Canadian Inuit living in the Arctic, who must travel over $2000 \mathrm{~km}$ for cancer therapy, are reportedly forgoing treatment altogether. ${ }^{2}$

Better understanding of the molecular biology of cancer and technologic advances in the ability to measure gene and protein abnormalities have recently led to the development of agents that target specific molecular pathways responsible for cancer growth and proliferation. The efficacy of these molecularly targeted therapies is largely governed by the importance of the targeted tumour pathway, which is increasingly determined by specific molecular biomarkers. For example, in the first-line treatment setting of advanced non-small-cell lung cancer, the oral epidermal growth factor receptor inhibitor gefitinib has been shown to improve progression-free survival, relative to chemotherapy, for some patients but not others. ${ }^{3}$

In molecularly defined subsets of patients, molecularly targeted agents are becoming the standard of care across many tumour sites, resulting in substantial improvements in progression-free survival and overall survival, ${ }^{4,5}$ particularly for patients with advanced forms of cancer not amenable to surgery. Although some molecularly targeted agents are delivered intravenously with chemotherapy, to enhance cytotoxicity, a number of these agents are taken as daily oral therapies.

For northern residents, the introduction of oral molecularly targeted agents, which can be delivered in the community and require less frequent monitoring and specialist reassessment than chemotherapy (every 6-8 wk v. 3 wk), is highly relevant. Furthermore, whereas patients receiving chemotherapy may experience lengthy or delayed toxic effects, necessitating access to 24-hour emergency health services, most oral agents have a short pharmacokinetic half-life, which allows for rapid reversal of treatment-induced toxic effects (e.g., rash, diarrhea, anorexia) on drug withdrawal. Oral therapies may therefore be a viable option in isolated northern communities.

For Canadian Inuit, the potential relevance of targeted cancer therapy is underscored by the availability of several targeted oral agents for some of the most common cancers affecting Arctic populations. For example, in Nunavut, lung cancer represents $39 \%$ of all cancer diagnoses, ${ }^{6}$ compared with $13 \%$ nationally. ${ }^{7}$ High rates of lung cancer among the Inuit are largely attributable to their high smoking rate $(>60 \%),{ }^{8}$ which is the focus of many public health promotion and cancer prevention initiatives in Nunavut. Of note, four oral molecularly targeted agents are currently approved by Health Canada for the treatment of advanced non-small-cell lung cancer in patients harbouring either epidermal growth factor receptor mutations (three agents) or translocations of the anaplastic lymphoma kinase gene (one agent), and one or more of these agents are funded by provincial and territorial drug benefit plans or federal programs (e.g., Non-Insured Health Benefits Program) in most jurisdictions in Canada. The influence of these oral molecularly targeted agents on clinical outcomes will ultimately depend on the molecular characteristics of lung cancer among the Inuit, which are currently unknown. Given their probable Asian ancestry and the high prevalence of epidermal growth factor receptor mutations in Asian populations with non-smallcell lung cancer, ${ }^{9}$ targeted therapy with these agents may represent an important treatment opportunity for the Inuit.
Competing interests:

Timothy Asmis has served as a consultant for Roche on projects outside the scope of this commentary. Glenwood Goss has received research grants from AstraZeneca and Roche for work outside the scope of this commentary, as well as honoria from AstraZeneca and Pfizer for attendance at advisory board meetings (as a board member). No other competing interests declared.

This article has been peer reviewed.

Correspondence to: Glenwood Goss, ggoss@ottawahospital.on.ca

CMAJ 2014. DOI:10.1503 /cmaj.131011 
Although some of the earlier molecularly targeted agents in oncology were approved without mandated biomarkers, it has become apparent that in many instances genetic profiling and mutational analysis are essential for their targeted, cost-effective delivery. As such, biomarker identification will likely be a requirement for regulatory approval of molecularly targeted agents in the future. Unfortunately, in Canada, the infrastructure to support molecular screening and early identification of patients eligible for targeted therapy is unevenly distributed across the provinces, and in some cases may depend on external financial subsidies. ${ }^{10}$ An ethical problem arises when approval of targeted therapies is limited to molecularly defined subsets, in the absence of uniform access to molecular testing and mechanisms to allow for the early identification of eligible patients. In the Canadian context, it is imperative that the Inuit and other northern residents be included in the debate on this issue, given the unique challenges they face in accessing cancer treatments. ${ }^{2}$

The survival gains achieved with targeted therapy for cancer in certain molecularly defined subsets have been astounding. Despite the challenges that may exist, national standards for molecular testing following a cancer diagnosis, as have been successfully implemented in other countries, ${ }^{11}$ should be developed in Canada. Screening and molecular testing for oral targeted therapies are particularly relevant to cancer care for Canadians in the North, who stand to reap substantial benefit from cancer treatment in the community. Concurrently, strategies to monitor patients must be developed to ensure the safe and effective delivery of personalized therapies in rural settings. In this context, enhanced oncology training for rural health care professionals and improved patient education will be important to avoid and manage acute treatmentinduced toxic effects, particularly given the higher incidence of such effects (e.g., rash, diarrhea) reported with some of the newer, more potent second-generation targeted therapies. ${ }^{12}$ In addition, stronger linkages with regional cancer centres must be developed and maintained using existing technologies such as telehealth, to avoid unnecessary travel and to provide the necessary support for health care providers in the North.

Canadians should have access to modern cancer therapies, regardless of where they live. With the introduction of orally administered targeted agents, there may be an opportunity to increase the proportion of northern patients getting access to effective anticancer therapies. Targeted therapy may also improve their quality of life, by reducing the travel burden associated with treatment and enabling treatment in the community. Finally, although molecularly targeted therapies are more expensive than most chemotherapy, the increased cost may be offset by a decrease in hospital admissions and a reduction in federally and provincially reimbursed travel and lodging, as a result of fewer trips to urban cancer treatment centres. With the right support mechanisms and molecular screening infrastructure, targeted therapy can be an important component of better cancer care for northern residents.

\section{References}

1. Crawford SM, Sauerzapf V, Haynes R, et al. Social and geographical factors affecting access to treatment of lung cancer. $\mathrm{Br}$ J Cancer 2009; 101:897-901.

2. Inuit and cancer: fact sheets. Ottawa $(\mathrm{ON})$ : Inuit Tapiriit Kanatami; 2009. Available: www.itk.ca/sites/default/files/private /factsheet-seriesFINAL2.pdf (accessed 2013 Oct. 11).

3. Mok TS, Wu YL, Thongprasert S, et al. Gefitinib or carboplatinpaclitaxel in pulmonary adenocarcinoma. $N$ Engl J Med 2009;361: 947-57.

4. Shepherd FA, Pereira JR, Ciuleau T, et al. Erlotinib in previously treated non-small-cell lung cancer. N Engl J Med 2005;353:123-32.

5. Motzer RJ, Hutson TE, Tomczak F, et al. Overall survival and updated results for sunitinib compared with interferon-alfa in patients with metastatic renal cell carcinoma. J Clin Oncol 2009; 27:3584-90.

6. Healey S, Plaza D, Osborne G. A ten-year profile of cancer in Nunavut, 1992-2001. Iqaluit (Nunavut): Department of Health and Social Services; 2003. Available: http://pubs.aina.ucalgary .ca/health/55692E.pdf (accessed 2013 Dec. 13).

7. Canadian Cancer Society, Advisory Committee on Cancer Statistics. Canadian cancer statistics 2013. Toronto (ON): Canadian Cancer Society; 2013. Available: www.cancer.ca/ /media /cancer.ca/CW/publications/Canadian\%20Cancer\%20Statistics /canadian-cancer-statistics-2013-EN.pdf (accessed 2013 Dec. 16).

8. Tait H. Aboriginal people's survey, 2006: Inuit health and social conditions. Ottawa (ON): Statistics Canada, Social and Aboriginal Statistics Division; 2008. Cat. no. 89-637-X. Available: www .nativiamericani.it/filevari/89-637-x2008001-eng.pdf (accessed 2014 Feb. 14)

9. Shigematsu H, Liu L, Takahashi T, et al. Clinical and biological features associated with epidermal growth factor gene mutations in lung cancer. J Natl Cancer Inst 2005;97:339-46.

10. Ellis PM, Verma S, Sehdev S, et al. Challenges to implementation of an epidermal growth factor receptor testing strategy for non-small-cell lung cancer in a publicly funded health care system. J Thorac Oncol 2013;8:1136-41.

11. Molecular genetic testing for equal access to targeted therapies in France in 2011. Boulogne-Billancourt (France): Institut national du cancer; 2012. Available: www.e-cancer.fr/publications/57 -soins/582-molecular-genetic-testing-for-equal-access-to-targeted -therapies-in-france-in-2011 (accessed 2013 Oct. 11).

12. Sequist LV, Yang JC, Yamamoto N, et al. Phase III study of afatinib or cisplatin plus pemetrexed in patients with metastatic lung adenocarcinoma with EGFR mutations. J Clin Oncol 2013; 31:3327-34.

Affiliations: Ottawa Hospital Research Institute (Spaans, Alvarez, Goss); Ottawa Hospital Cancer Centre (Asmis, Goss); Department of Medicine (Asmis, Alvarez, Goss), University of Ottawa, Ottawa, Ont.

Contributors: Johanna Spaans and Glenwood Goss conceived the article, which was jointly prepared with Timothy Asmis and Gonzalo Alvarez. Gonzalo Alvarez provided Nunavut content expertise, and Timothy Asmis and Glenwood Goss provided content expertise on targeted cancer therapies. Johanna Spaans and Glenwood Goss generated the first draft of the manuscript, which was edited and revised by all authors at all stages. The final manuscript was reviewed and approved by all authors. 